\title{
GRASS COVER CHANGE MODEL BASED ON CELLULAR AUTOMATA
}

\author{
Shuai Zhang ${ }^{*}$, Jingyin Zhao, Linyi Li \\ Digital Agricultural Engineering Technological Research Center, Shanghai Academy of \\ Agricultural Sciences, Shanghai, China, 201106 \\ * Corresponding author, Address: Digital Agricultural Engineering Technological Research \\ Center, Shanghai Academy of Agricultural Sciences, 2901 Beidi Road, Shanghai, 201106, \\ P. R. China, Tel: +86-21-62208434,Fax: +86-21-62208434, Email: zhangshuai@saas.sh.cn
}

Abstract: This research attempt to establish a grass cover change model based on cellular automata. It took the relationship between elevation, slope, aspect, settlement, road, water system and grass cover change as the foundation of the model, the dynamic progress of grass cover change was expressed by using cellular automata, the grass cover change model based on the basic geographical control condition which has been mentioned in above paragraph was constructed. The grass cover state of Madoi County in 2003 was simulated, and has been compared with the actual state of Madoi County in 2003. It was found that the grass cover change model has a high precision. The value of kappa index has reach 0.8801 .

Keywords: cellular automata, grass cover change

\section{INTRODUCTION}

Cellular automata was conceived and advanced by John Von Neumann during the 1950s. Cellular automata is a kind of dynamic model which is discrete, it has not been confirmed by strictly defined physics equation or function, but a set rule of construct model, it is a sum of a kind model. Because it has reciprocity between different cells, cellular automata is fit to simulate complex system, at the same time it is also has spatial conception which can make the change of object visibility, and it is fit to simulate changes in large scale.

Zhang, S., Zhao, J. and Li, L., 2008, in IFIP International Federation for Information Processing, Volume 259; Computer and Computing Technologies in Agriculture, Vol. 2; Daoliang Li; (Boston: Springer), pp. 825-832. 
We can characterize cellular automata as follows:

Cell-Cell is the basic element of cellular automata, and each cell has a set of states. The states could be a binary system; it also could be internal variables.

Grid-Grid is a aggregate of cells, it could be 1-dimensional, 2-dimensional or multidimensional.

Neighborhood-The neighborhood of cell is a collection of cells around the cell, they will impact the state of the cell at next time. In 1-dimensional cellular automata the neighborhood is confirmed by radius. In 2-dimensinal cellular automata the neighborhood has three style, they are Von.Neumann, Moore and prolate Moore which are showed in Fig. 1.

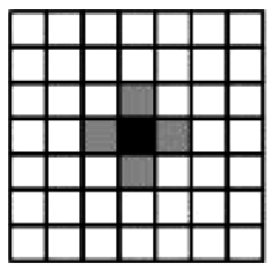

(a) Von Keumann

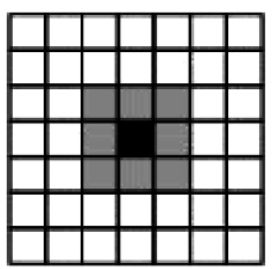

(b) Koore

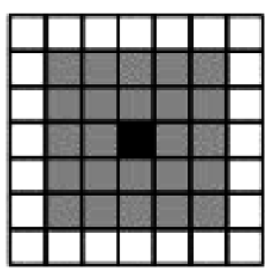

(c) Drolate Hore

Fig. 1. Neighborhood model of cellular automata

Rule-The state of a cell is determined by a set of rules which depend on the current state of cell and the state of the neighborhood cells.

Time-Time is a set of internal integers.

Cellular automata based models have been used to study forest fires, soil erosion and so on.

Li use the cellular automata which based on nerve network simulate the complex system of land use and land cover change in zhujiang delta ( $\mathrm{Li}$ et al., 2005). Chen has used the cellular automata model based on $3 \mathrm{~s}$ technology to simulate the hungriness change, simulate and forecast the trend of the hungriness change trends in Beijing and adjacent (Chen et al., 2004). Fang has analysed the land cover and land change data in Peoria area from 1993 to 2000 (Fang et al., 2005). Filho has simulated the landscape change in Amazon area with stochastic cellular automata (Filho et al., 2004).

Cellular automata has been used in many fields, but is has not been used to simulate the change of grass cover. This paper presents an cellular automata model to simulate grass cover change in Madoi County.

Madoi County, which is located in the source region of yellow river, is the main part of the source region of yellow river, it is between $96^{\circ} 50^{\prime}-$ $99^{\circ} 32^{\prime} \mathrm{E}, 33^{\circ} 52^{\prime}-35^{\circ} 39^{\prime} \mathrm{N}$, total area of Madoi County is $2.45 \times 10^{4} \mathrm{~km}^{2}$. In recent years, the source region of yellow river has become an important research focus area, the degradation in this region is significantly serious in past decades (Dong et al., 2002). Degradation has a grate impact on the ecosystem health in the source region of yellow river (Feng et al., 2004). 


\section{MATIERIALS AND METHOD}

\subsection{Data and pretreatment}

We used the DEM data which resolution is $100 \mathrm{~m}$. With the spatial analyst in Arcmap we can get the slope and aspect data which resolution are also $100 \mathrm{~m}$. Use the reclassify function in spatial analyst model the elevation data was divided by a interval of $100 \mathrm{~m}$, then the slope data was reclassified by $3^{\circ}$, $5^{\circ}, 8^{\circ}, 12^{\circ}, 15^{\circ}, 18^{\circ}, 21^{\circ}, 25^{\circ}, 30^{\circ}, 35^{\circ}$, the aspect data was reclassified by north, northeast, east, southeast, south, southwest, west, northwest; the distance buffer grid was created with the distance command by use the buffer distance is $100 \mathrm{~m}$.

Put the grass cover change data overlap with the elevation, slope, aspect, settlement, road and water system data, the grass cover change statistic of each zonal grid, the ratio of the change area and the zonal grid area, which is short for the rate of change in the below paragraph. We fit each factor with the rate of changes by Origin.

\subsection{Model establishment}

\subsubsection{Basic geographical control condition}

We fit the basic geographical control condition with the rate of change by use Origin. The result was showed in Fig. 2-7.

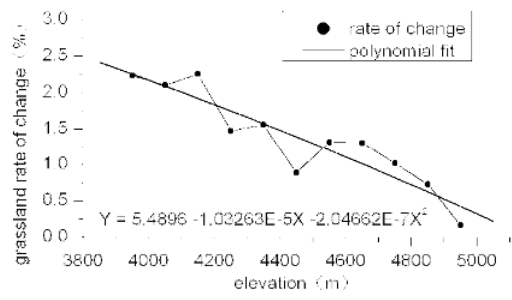

Fig. 2. Fitting of elevation and rate of change

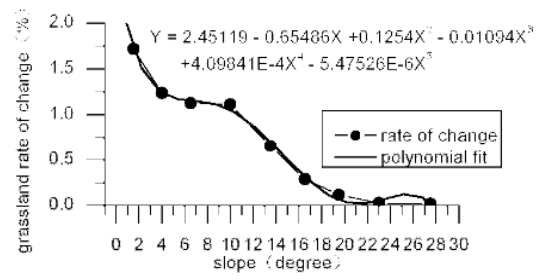

Fig. 3. Fitting of slope and rate of change 


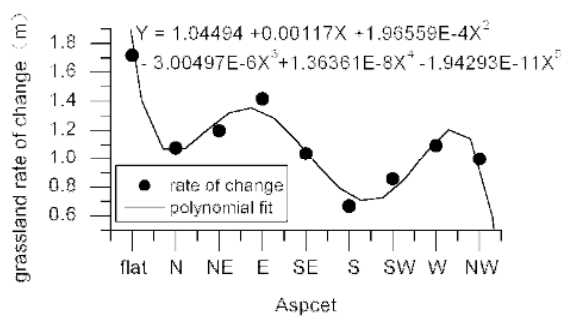

Fig. 4. Fitting of aspect and rate of change

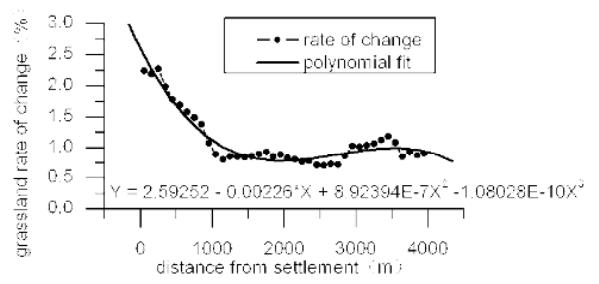

Fig. 5. Fitting of settlement and rate of change

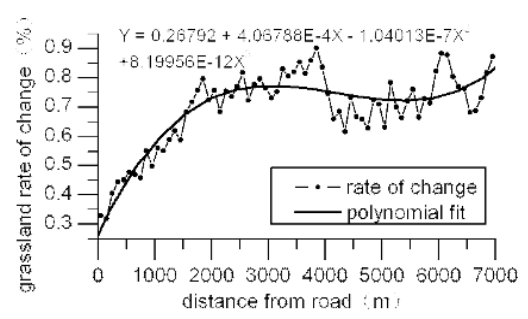

Fig. 6. Fitting of road and rate of change

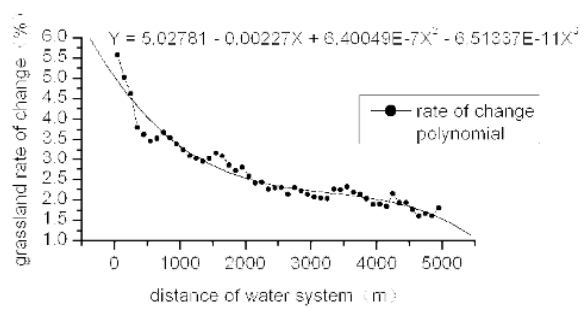

Fig. 7. Fitting of water system and rate of change

It has been found that, with the raise of the elevation, the rate of change has present a downtrend; the rate of change is more high in where slope is lower, the rate of change has a inverse relation with the distance from settlement within $1000 \mathrm{~m}$, it has little change upwards $1000 \mathrm{~m}$; the rate of change has increased as the distance from road increased; the rate of change has increased rapidly as the distance from water system within $2000 \mathrm{~m}$. 


\subsubsection{Rules of model}

Based on the analysis, this paper has established a grass cover change model by use cellular automata, which has make hypothesis before modeling as follows:

(1) The grade of grass cover will reduce when the rate of change has reached the threshold value for 3 years, and the conversion will not span grade.

(2) The conversion of shrubbery to grass will take place only when the rate of change has reached the threshold value for 5 years.

(3) The sandlot expand $100 \mathrm{~m}$ every 3 years, but only the low cover grassland around sandlot will turn into sandlot, other types will not be influenced by the expand of sandlot.

(4) Each base geographical control condition is independent.

(5) Only the conversion relationship between shrubbery, grass and sandlot were considered, the conversion relationship between other types are not considered for the moment.

(6) The impact of climate and policy are not considered in this paper.

According to the concept and theory of cellular automata, this paper has set the construction of model.

(1) Cell - The shape of the cell is square, and its resolution is $100 \mathrm{~m}$.

(2) Cell space - The cell space is the research area.

(3) State - Each cell has two states sometime: 0 and 1.0 stands for the type of cell will not change, 1 stands for the type of cell will change. Each cell has a change probability, which show the probability of the change.

(4) Time - The time interval is one year.

(5) Neighborhood - Use the prolate Moore model.

(6) Rule - For each cell, the change probability is the average of the probability of neighborhood.

The process of cellular automata is as follows:

(1) Fit the elevation, slope, aspect, settlement, road, water system with grass cover change data, get the chart of influence factor of grass cover change, and make standardization of it.

(2) Delete water body and other type from grass cover map.

(3) Compute the grass cover change probability chart of current year by using the chart of influence factor map.

(4) Simulate the uncertainty of grass cover change by using random function.

(5) The threshold value was confirmed at first, then the finally threshold value was confirmed after simulate and compare, compute the rate of change which big than the threshold value, get the map of grass cover change in current year. 
(6) Get the grass cover map in next year by overlap the grass cover change map and grass cover map.

\section{RESULTS AND DISCUSSION}

Input the grass cover data of year 1990, compute the grass cover data of year 2003, the result was showed in Fig. 9. And the actual state of grass cover in year 2003 was showed in Fig. 8.

Input the compute result in ENVI to compute Kappa index, the Kappa index between the simulate data of year 2003 and the actual data of year 2003 has reached 0.8801 .

The compute result was compared with actual data in Table 1, low cover grassland and sandlot has difference quantitatively.

Table 1. The comparison between simulate value and actual value

\begin{tabular}{lcc}
\hline & Simulate value & Actual value \\
\hline High cover grassland & 570887 & 556682 \\
Mid cover grassland & 426285 & 423009 \\
Low cover grassland & 889516 & 927951 \\
Shrubbery & 13091 & 12922 \\
Water body & 323117 & 327573 \\
Sandlot & 154805 & 126949 \\
Other type & 70519 & 72636 \\
\hline
\end{tabular}

The units for simulate value and actual value are $\mathrm{km}^{2}$.

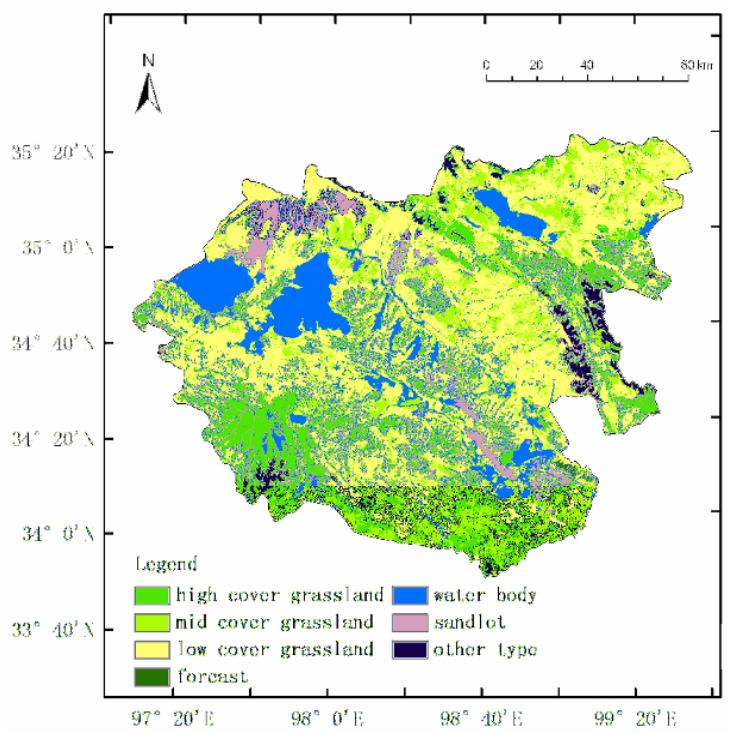

Fig. 8. Actual state of grass cover 


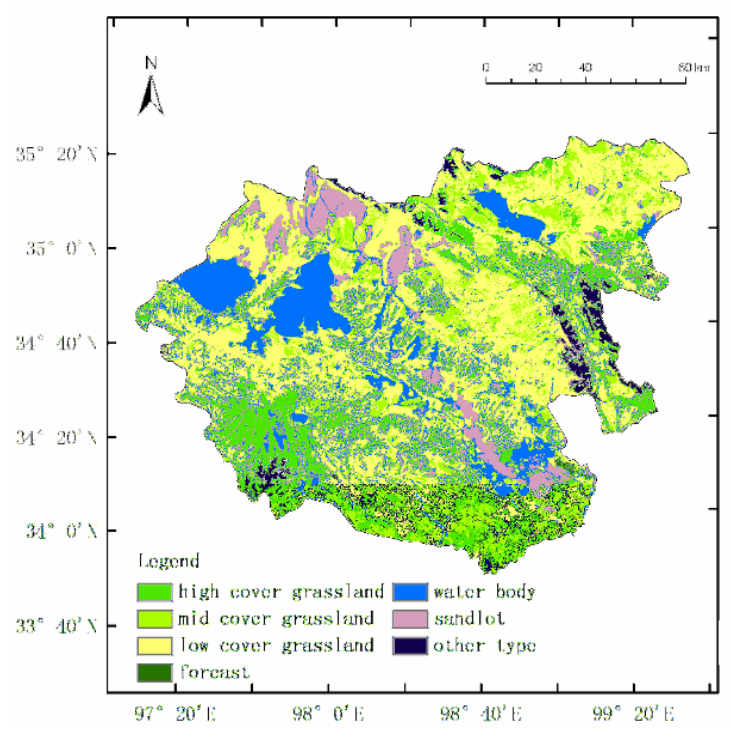

Fig. 9. Simulate state of grass cover

\section{CONCLUSIONS AND FUTURE WORKS}

This paper has established a set of rules for grass cover change according to the theory of cellular automata, and it was based on the considering of influence of the basic geographic control condition such as elevation, slope, aspect, settlement, road, water system on grass cover change. Then we construct a dynamic model to express the dynamic change of grass cover, the grass cover state of Madoi County in 2003 was simulated by using this grass cover change model, and it was compared with the actual state of grass cover of Madoi County in 2003, it was found that the precision was high, the Kappa index between simulate result and actual value has up to 0.8801 , it has show that cellular automata could simulate the grass cover change was predominated adequately.

\section{ACKNOWLEDGEMENTS}

We are grateful to colleagues who provide the grass cover data used in the present study - Qinghai sanjiangyuan research group, Institute of Geographic Sciences and Natural Resources Research. This work is supported by Research and Demonstrate for Key Technology of Modern Country Information Project (Contract Number: 2006BAD10A11) of National Science \& Technology Pillar Program. 


\section{REFERENCES}

Chen J P, Ding H P, Wang J W, Li Q, Feng C. Desertification Evolution Modeling through the Integration of GIS and Cellular Automata. Journal of Remote Sensing, 2004, 8: 254260 (in Chinese)

Dong S C, Zhou C J, Wang H Y. Ecological crisis and countermeasures of the Three River' Headstream Region. Journal of Natural Resource, 2002, 17: 713-720 (in Chinese)

Fang S F, Gertnera G Z. The impact of interactions in spatial simulation of the dynamics of urban sprawl. Landscape and Urban Planning, 2005, 73: 294-306

Feng J M, Wang T, Qi S Z, Xie C W. Study on Dynamic Changes of Land Desertification and Causal Analysis in Source Region of Yellow River - a Case Study of Maduo County. Journal of Soil and Water conservation, 2004, 18: 141-145 (in Chinese)

Filho B S, Gustavo C C, Ca'ssio L P. Dinamica: a stochastic cellular automata model designed to simulate the landscape dynamics in an Amazonian colonization frontier. Ecological Modelling, 2002, 154: 217-235

Li X, Ye J A. Cellular Automata for simulation complex land use systems using neural networks. Geographical Research, 2005, 24: 19-27 (in Chinese) 